\title{
Jogo Digital na inclusão de alunos com deficiência
} visual

\section{Digital games in the inclusion of students with visual impairment}

\author{
BRUNO CESAR SOARES DILE ROBALINHO \\ Colégio Pedro II \\ CHRISTINE SERTÃ COSTA \\ Colégio Pedro II
}

\begin{abstract}
Resumo: Neste artigo apresentamos o processo de construção de um jogo digital criado de forma participativa com alunos com deficiência visual (cegos e de baixa visão) de uma escola pública de referência do Rio de Janeiro, através do Jogavox, integrado ao Dosvox. O trabalho visa ações pró-ativas de inclusão e um olhar para os atuais discentes nativos digitais, que já incorporam um mundo informatizado e tecnológico. O objetivo deste trabalho é obter a percepção dos alunos com relação à validade deste instrumento pela sua usabilidade e ludicidade além de promover a inclusão. Pesquisas bibliográficas mostram que a temática de jogos digitais é prioritariamente de entretenimento, mas acreditamos ser interessante seu uso para fins pedagógicos. Utilizamos como metodologia a orientação qualitativa no enfoque críticoparticipativo, onde os alunos experimentaram e contribuíram na criação desse jogo. Nesse processo, consideramos o produto educacional como instrumento ou recurso para a evolução da inclusão no que tange a tecnologia digital. Esperamos que este modelo de jogo contribua com o ensino inclusivo de saberes diversos visto que sua usabilidade é simples e possibilita adequações. O Jogo mostrou-se adequado ao objetivo proposto.
\end{abstract}

Palavras-chave: Jogavox. Inclusão. Deficiência Visual. Jogo digital. Ludicidade.

Abstract: In this article we present the process of constructing a digital game created in a participative way with visually impaired students (blind and low vision) of a public reference school in Rio de Janeiro through the Jogavox, integrated with Dosvox. The work aims at proactive inclusion actions and a look at the current digital native students, who already incorporate a computerized and technological world. The objective of this work is to obtain the students' perception regarding the validity of this instrument for its usability and playfulness in addition to promoting inclusion. Bibliographical researches show that the theme of digital games is primarily entertainment, but we believe its use is interesting for educational purposes. We used as methodology the qualitative orientation in the critical-participative approach, where the students experimented and contributed in the creation of this game. In this process, we consider the educational product as an instrument or resource for the evolution of inclusion in digital technology. We hope that this game model contributes to the inclusive teaching of diverse knowledge since its usability is simple and allows adjustments. The Game proved to be adequate to the proposed goal.

Keywords: Jogavox. Inclusion. Visual impairment. Digital games. Playfulness.

ROBALINHO, BRUNO CESAR SOARES DILE; CHRISTINE SERTÃ COSTA. Jogo Digital como alternativa para inclusão de alunos com necessidades educacionais específicas. Informática na Educação: teoria \& prática, Porto Alegre, v. 22, n. 1, p. 60-78, jan./abr. 2019. 


\section{Introdução}

O jogo em ambientes digitais é algo presente na vida dos estudantes do século XXI, tendo em vista que estes nasceram na era digital sendo inclusive conhecidos como nativos digitais. Mas, ainda hoje, o uso destes jogos é majoritariamente voltado para o entretenimento de estudantes com ou sem alguma deficiência. Além disso, é difícil encontrarmos jogos digitais que sejam verdadeiramente inclusivos, ou seja, que possam ser utilizados simultaneamente por pessoas com e sem deficiência.

As pessoas com deficiência nos últimos 30 anos têm ampliado seus direitos e garantias como cidadãos plenos na sociedade brasileira. A chamada fase da inclusão teve como marco inicial a Constituição Federal (CF) de 1988 (BRASIL, 1988) que tratou essa questão de modo amplo e difuso. Porém um avanço, embora ainda não satisfatório, tem ocorrido ao longo do tempo.

Ao falar em educação especial na perspectiva inclusiva, devemos traçar uma linha do tempo citando algumas legislações e eventos que favoreceram este processo. Em 1990, dois anos após a CF, aconteceu a Conferência Mundial de Jomtien - um encontro que promoveu a educação para todos. Neste mesmo ano, o Estatuto da Criança e Adolescente (ECA) foi promulgado no Brasil. Em 1994, foi realizada a Conferência Mundial de Salamanca, cujo cerne foi a Educação Especial. Em 1996, a Lei de Diretrizes e Bases da Educação Nacional foi promulgada em consonância com o processo de inclusão. Em 2004, o Decreto da Promoção de acessibilidade às pessoas portadoras de deficiência e com acessibilidade reduzida nos traz, em seu capítulo II, a definição de cegueira e baixa visão. Em 2006, foi lançada a Convenção dos direitos das Pessoas com Deficiência e, finalmente, em 2015, a Lei Brasileira da Inclusão da Pessoa com Deficiência (LBI) é instituída.

Como problema de pesquisa, temos a seguinte questão: os jogos digitais podem contribuir para a inclusão, na rede regular de ensino, de alunos com deficiência visual? No intuito de atender a esta questão, buscamos fundamentos da literatura no que concerne na implementação de tecnologias digitais no âmbito escolar e também através da experimentação prática na construção cooperativa de um jogo digital, visando uma maior interação com o alunado. Portanto, nosso objetivo neste trabalho foi obter a percepção dos alunos com relação à validade deste instrumento pela sua usabilidade e ludicidade ao lidar com conteúdos escolares, além de promover a inclusão.

\section{Fundamentação Teórica}

A história das pessoas com deficiência passou e ainda passa por diversos movimentos afirmativos e lutas sociais. A forma como a sociedade percebe essas pessoas têm sofrido transformações significativas no tempo. Estes momentos são divididos por Sassaki (1997) em quatro fases nomeadas de exclusão, segregação, integração e inclusão.

Na fase da exclusão, anterior ao segundo reinado, a pessoa com deficiência era totalmente excluída da sociedade. 
Na fase da segregação, reinado de Dom Pedro II, a pessoa com deficiência passou a ter acesso à escola, mas estas eram especiais como, por exemplo, o Instituto Benjamin Constant (IBC) e o Instituto Nacional de Educação de Surdos (INES). Ambos no Rio de Janeiro.

Na fase da integração, começaram a surgir turmas especiais em escolas regulares. Por vezes, estas pessoas também estavam na sala comum, conforme o artigo 88 da LDBEN (BRASIL, 1961): "A educação de excepcionais, deve, no que for possível, enquadrar-se no sistema geral de educação, a fim de integrá-los na comunidade".

As experiências e a luta pela concretização das políticas públicas das pessoas com deficiência deram origem à quarta fase, a fase da inclusão, na qual a pessoa com deficiência passou a ser incluída na sociedade e também na sala de aula.

De forma a termos uma inclusão efetiva, a LBI (BRASIL, 2015), em seu art. 74, afirma que "é garantido à pessoa com deficiência acesso a produtos, recursos, estratégias, práticas, processos, métodos e serviços de tecnologia assistiva ${ }^{1}$ (TA) que maximizem sua autonomia, mobilidade pessoal e qualidade de vida".

Em relação ao ambiente educacional, a educação especial, de acordo com o artigo 58 da LDBEN (BRASIL, 1996), é "a modalidade de educação escolar oferecida preferencialmente na rede regular de ensino, para educandos com deficiência, transtornos globais do desenvolvimento e altas habilidades ou superdotação". Dentre estes educandos, focaremos na inclusão daqueles que têm deficiência visual (DV), seja o educando cego ou o de baixa visão.

As pessoas com deficiência visual, ao interagirem com o ambiente ao seu redor, lidam com o mundo de uma forma diferente daqueles que não possuem tal deficiência. De modo geral, os sentidos que ganham destaque são, de acordo com Ochaíta e Espinosa (2004), a audição e o tato, sendo este último, um dos principais meios de interação com o mundo.

Em termos materiais, o sentido do tato, de curto alcance, é utilizado para conhecer o objeto, seu tamanho, textura, peso etc. Por outro lado a pessoa vidente pode conhecer o objeto a distância. No que tange à audição, ouvir auxilia na comunicação e também permite a localização de pessoas e objetos. Entretanto, se o obstáculo for silencioso, este sentido não fornecerá informação suficiente.

Estas características do modo como estes sentidos são utilizados já nos indica que o processo de aprendizagem da pessoa com deficiência visual, em certos contextos, pode ser mais lento.

Ao falarmos da interação com a tecnologia digital da pessoa cega, o sentido preponderante é o da audição. Esta interação permite o uso de mecanismos que o integrem à comunicação pessoal, ao estudo, às notícias e entretenimentos. Jogos digitais são um desses mecanismos. Essa integração pode se dar por meio de emissão sonora própria ou com o uso de ledores de tela ${ }^{2}$, como NVDA e JAWS ${ }^{3}$ ou ainda com o Sistema Dosvox ${ }^{4}$. Cabe ressaltar ainda que, para as

\footnotetext{
${ }^{1}$ tecnologia assistiva ou ajuda técnica: produtos, equipamentos, dispositivos, recursos, metodologias, estratégias, práticas e serviços que objetivem promover a funcionalidade, relacionada à atividade e à participação da pessoa com deficiência ou com mobilidade reduzida, visando à sua autonomia, independência, qualidade de vida e inclusão social. Art. $3^{\circ}$, inciso III da LBI (BRASIL, 2015);

2 Ledores de tela são programas capazes de transformar em áudio a indicação de componentes da tela além de falar o que nelas está escrito.

${ }^{3}$ NVDA (NonVisual Desktop Access), gratuito. JAWS (Job Access With Speech), pago.

${ }^{4}$ É um sistema para microcomputadores da linha PC que se comunica com o usuário através de síntese de voz, viabilizando, deste modo, o uso de computadores por deficientes visuais, que adquirem assim, um alto grau de independência no estudo
} 
pessoas com baixa visão, o recurso imagético ainda pode e deve ser utilizado e sua eficácia dependerá da severidade da deficiência.

Outra temática que surge naturalmente ao nos referirmos a jogos é a ludicidade. Huizinga (2010) nos traz algumas reflexões importantes sobre este tema afirmando que é algo inerente à própria construção humana. Para este autor,

\begin{abstract}
seria mais ou menos óbvio, mas também um pouco fácil, considerar 'jogo' toda e qualquer atividade humana. [...] Não vejo, todavia, razão alguma para abandonar a noção de jogo como um fator distinto e fundamental, presente em tudo o que acontece no mundo. Já há muitos anos que vem crescendo em mim a convicção de que é no jogo e pelo jogo que a civilização surge e se desenvolve. (HUIZINGA, 2010, prefácio)
\end{abstract}

O termo ludicidade necessita de um esclarecimento adicional tendo em vista que é bastante comum ligar este termo à brincadeiras, jogos e entretenimentos de forma livre e descompromissada e cairmos no senso comum que aponta que "em nossa maneira de pensar, o jogo é diametralmente oposto à seriedade" (HUIZINGA, 2010, p. 8). Entretanto, o autor nos faz refletir e perceber que, em muitos casos, esta afirmação não é verdadeira. Um exemplo bastante ilustrativo é o jogo de xadrez, cuja seriedade é algo inerente ao próprio jogo.

Sendo assim, "o jogo distingue-se da vida 'comum' tanto pelo lugar quanto pela duração que ocupa" (HUIZINGA, 2010, p. 12) e não pela sua seriedade ou entretenimento. Isto nos leva a uma questão maior, na qual o jogo deve proporcionar imersão, comprometimento e interesse de quem fizer uso dele.

Num ambiente educacional, os jogos digitais não devem ser subutilizados de modo a ficarem presos ao sistema estudar-decorar. Devem sim, permitir que os alunos participem de forma efetiva na construção do conhecimento. Sendo assim,

\footnotetext{
não basta acreditar que a simples introdução de um jogo qualquer seja o suficiente para uma nova abordagem que motive e faça com que os alunos construam conhecimento: é preciso muito trabalho para que ocorra uma verdadeira integração entre os jogos e a Educação, e, a partir desse processo, uma mudança no paradigma escolar. (PAULA; VALENTE, 2016 p.3)
}

Estes jogos podem ser utilizados para ensinar e aprender conteúdos particulares, desenvolver alguma nova habilidade ou ainda atender características especificas dos alunos, tendo deficiência ou não. Um exemplo é um aluno que se dispersa facilmente, por alguma dificuldade ou desinteresse, em sala de aula e, para ele, o jogo pode ser usado para desenvolver a concentração.

Hildebrand e Oliveira elencam uma série de características importantes que podem ser trabalhadas e vivenciadas ao se utilizar jogos digitais no ambiente escolar, entre elas "diversão, imersão em outra realidade, atemporalidade, fusão, exploração, domínio, estimulação, frustração ótima, aprendizagem, tomada de decisões, desafios das habilidades e a volta a realidade" (HILDEBRAND e OLIVEIRA, 2018, p. 115).

Em relação a alunos com deficiência, em especial a alunos com deficiência visual, faz-se necessário modelar o jogo de forma a priorizar a informação auditiva. Porém, não devemos ignorar os recursos visuais, pois no grupo participante da pesquisa há também alunos com baixa

e no trabalho. [...] A interação do usuário dá-se através de entradas via teclado. Dentre seus programas, temos editor de texto, calculadora, jogos, navegador de internet, email etc. (http://intervox.nce.ufrj.br/dosvox) 
visão, que, como já dito, poderão tirar proveito destes recursos a depender da severidade de sua deficiência.

A construção do conhecimento com o uso da tecnologia também encontra respaldo na visão de Seymor Papert (1993). Em seu livro A Máquina das Crianças - Repensando a Escola na Era da Informática, ele aborda o paradigma construcionista, com eco em Valente (1998), onde o aluno deve ter um papel ativo durante o processo de aprendizagem. Sobre essa abordagem tecnológica, o autor afirma que,

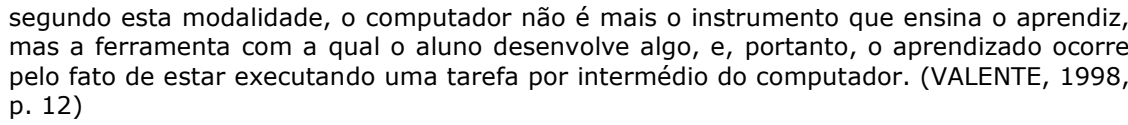

segundo esta modalidade, o computador não é mais o instrumento que ensina o aprendiz, mas a ferramenta com a qual o aluno desenvolve algo, e, portanto, o aprendizado ocorre pelo fato de estar executando uma tarefa por intermédio do computador. (VALENTE, 1998, p. 12)

Papert critica a educação tradicional e expõe a perspectiva da visão construcionista quando afirma que

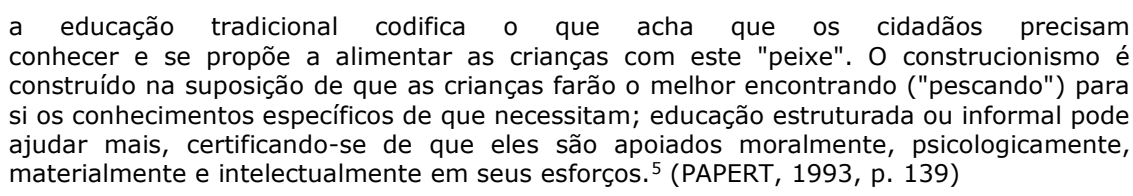
construído na suposição de que as crianças farão o melhor encontrando ("pescando") para si os conhecimentos específicos de que necessitam; educação estruturada ou informal pode ajudar mais, certificando-se de que eles são apoiados moralmente, psicologicamente, materialmente e intelectualmente em seus esforços. ${ }^{5}$ (PAPERT, 1993, p. 139)

A partir deste pensamento e após ter migrado para os Estados Unidos na década de 1960, indo trabalhar no Massachusetts Institute of Technology (MIT), Papert desenvolveu a primeira versão da linguagem Logo, em 1967, neste novo paradigma. Esta linguagem - interpretada e interativa - permite que uma sequência de ordens em linguagem natural seja enviada a um robô [com formato de tartaruga], possuidor de uma caneta, que as cumpre fielmente, permitindo que se façam desenhos / gráficos em um papel. Versões gráficas dessa linguagem foram desenvolvidas para serem usadas em computadores e atualmente estão disponibilizadas em diversos idiomas.

Nesta mesma linha, Hildebrand e Oliveira (2018) apontam que os orientadores estimulem seus alunos a construírem seus conhecimentos, de forma ativa, colaborativa e participava e que os discentes não tenham um comportamento passivo de apenas receber conteúdos já prontos.

Com base nestas ideias, produzimos um protótipo de um jogo de tabuleiro, cujo nome é Trilha do Conhecimento ${ }^{6}$, cuja tela da versão 2.0 (a mais atual) está apresentada na figura 1.

\footnotetext{
${ }^{5}$ Traditional education codifies what it thinks citizens need to know and sets out to feed children this "fish." Constructionism is built on the assumption that children will do best by finding ("fishing") for themselves the specific knowledge they need; organized or informal education can help most by making sure they are supported morally, psychologically, materially, and intellectually in their efforts.

${ }^{6}$ Para obter o jogo, solicite-o através de brunopedagogo.cp2@gmail.com.
} 


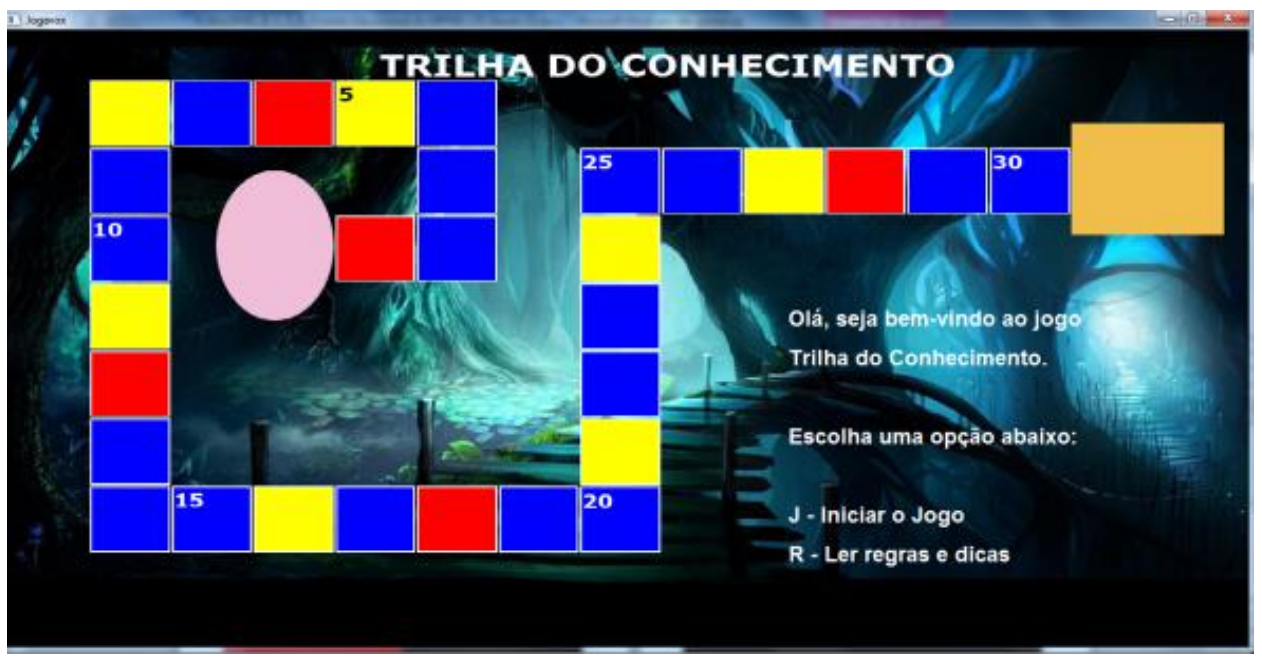

Fonte: o Autor, 2018.

As ideias e reflexões postas anteriormente dão sustentação e significado ao desenvolvimento desta pesquisa. Apresentamos na próxima seção uma breve história da evolução do Jogavox, programa essencial para o desenvolvimento deste jogo.

\section{A evolução do Jogavox}

O programa Jogavox, parte integrante do Sistema Dosvox, teve sua construção inicial focada nas pessoas com deficiência visual, uma vez que faz uso da síntese de voz - característica inerente do sistema Dosvox. Entretanto, com suas constantes modificações e evoluções, cada vez mais aspectos visuais estão sendo incorporados. Com isto, incluem-se pessoas cuja deficiência visual é a baixa visão e também o público em geral.

Desenvolvido inicialmente por Érica Cunha em sua dissertação (CUNHA, 2007), o Jogavox continha uma parte voltada à criação e simulação em Windows e uma parte voltada à execução do jogo dentro do Dosvox. Neste momento embrionário, o aluno com deficiência visual só tinha acesso ao jogo pronto por meio do sistema Dosvox.

Em 2009, Lidiane Silva, durante seu curso de especialização (SILVA, 2009), participou da criação e implementou o Jogavox totalmente integrado ao Dosvox. Isto deu autonomia às pessoas com deficiência visual que passaram a poder criar, executar e jogar jogos disponibilizados no novo programa.

Há duas formas de produzir jogos no Jogavox: através de formulários ou por um roteiro.

O método do preenchimento de formulários era o único disponível na versão inicial do Jogavox. A favor deste método está a facilidade do preenchimento dos campos uma vez que todos já aparecem listados na tela (figura 2) e também são lidos pelo sintetizador de voz. As limitações desta forma estão no fato de não se ter a percepção global do jogo durante sua criação e, especialmente, do processo de criação ser bastante trabalhoso. 
Figura 2 - Preenchimento por formulário (Lugar e Slide)

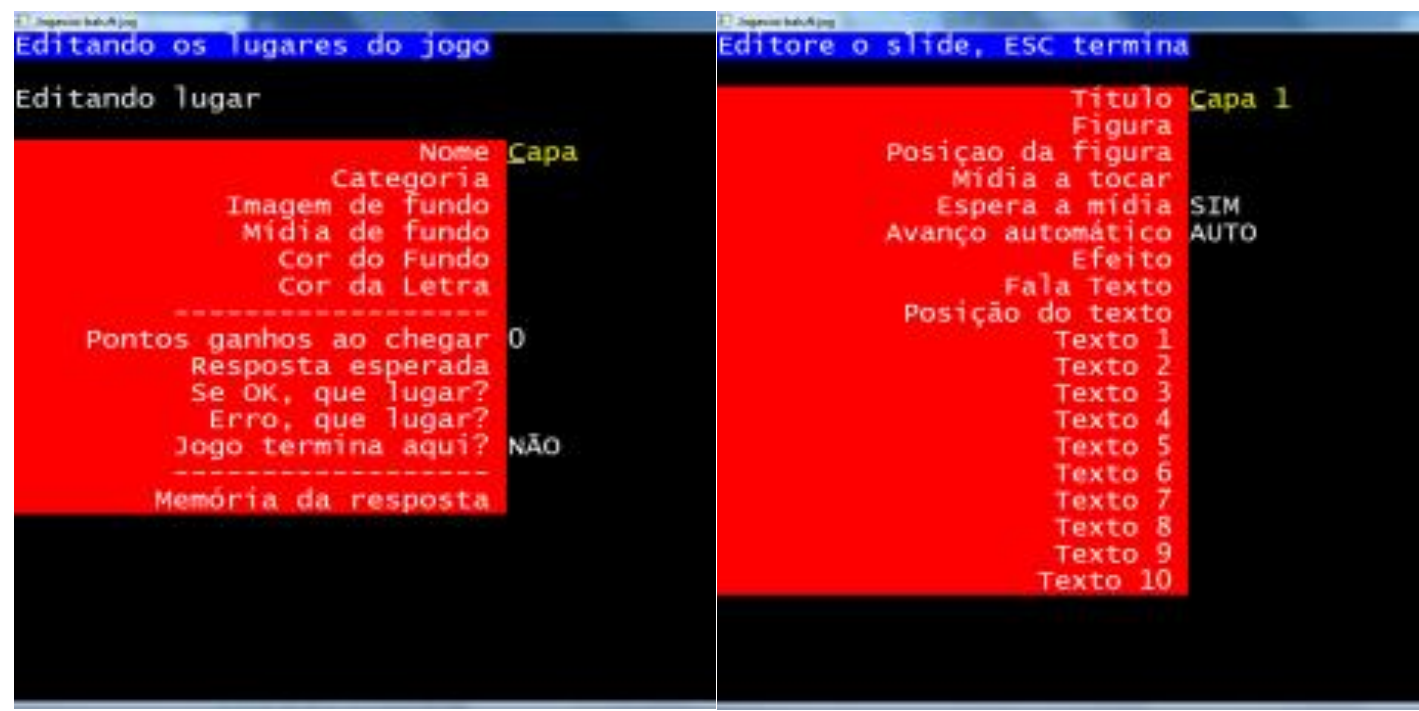

Fonte: O Autor

Buscando um modo de simplificar o trabalho de criação de jogos, sem precisar ficar entrando e saindo de várias telas para editar o jogo, foi elaborado o método de criação por roteiro. 0 roteiro é um arquivo comum de texto com uma estrutura bem objetiva (figura 3), na qual a pessoa digita diretamente o jogo - seus $\operatorname{comandos}^{7}-\mathrm{e}$, posteriormente, importa este arquivo para o Jogavox para que possa ser utilizado.

Figura 3 - Esquema de um Roteiro

\begin{tabular}{|c|c|}
\hline $\begin{array}{l}\text { Título } \\
\text { Autor }\end{array}$ & Cabeçalho \\
\hline ---- & \\
\hline $\begin{array}{l}\text { Início } \\
*\end{array}$ & \\
\hline$\underset{*}{\text { Slide1 }}$ & \\
\hline Slide2 & Lugar 1 \\
\hline$*$ & \\
\hline Slide3 & \\
\hline $\begin{array}{l}\text { Casa } \\
*\end{array}$ & Lugar 2 \\
\hline $\begin{array}{l}\text { Slide1 } \\
---\end{array}$ & \\
\hline $\begin{array}{l}\text { Quintal } \\
*\end{array}$ & Lugar 3 \\
\hline Slide 1 & \\
\hline
\end{tabular}

Fonte: O Autor.

\footnotetext{
7 Podem ser encontrados no manual Manual básico de criação de roteiros para produção de jogos no Sistema Jogavox. Disponível em: http://intervox.nce.ufrj.br/ rubens.dosvox/Site_Jogavox/Manuais/Manual_do_Roteiro_Jogavox-01-082014.pdf. Acesso em: 12 set. 2018.
} 
Com o passar do tempo, o Jogavox tem se tornado mais robusto. Na versão 3.0, em vigor, "tem a parte nova, que é a agregação do Script. O Script é uma ferramenta que você agrega ao jogo para ele fazer operações, cálculos e decisões lógicas. Ele é um complemento." (BORGES apud SILVA, 2017, p. 138).

\section{Procedimentos Metodológicos}

Configurando-se como uma pesquisa qualitativa no enfoque crítico-participativo com visão histórico-estrutural, os pesquisadores atuaram diretamente com alunos com deficiência visual do Ensino Médio de uma escola de referência na cidade do Rio de Janeiro. A escolha desta metodologia é pelo fato do interesse de estudo não estar apenas voltado aos alunos em si, mas também em salientar a transformação da realidade (TRIVIÑOS, 1987).

A decisão por este grupo de alunos não foi aleatória, tendo em vista que, na nossa prática profissional, aprendemos que materiais "alternativos" desenvolvidos para alunos com deficiência, em geral, atendem a todos os alunos. Dizemos que "se é bom para o deficiente, é bom para todos".

Em relação à pesquisa qualitativa, apontamos cinco pontos cruciais.

- Tem o ambiente natural como fonte direta dos dados e o pesquisador como instrumentochave;

- É descritiva;

- A preocupação é com o processo e não simplesmente com os resultados e o produto;

- Possibilita análise indutiva de dados;

- A busca pelo significado é o essencial nesta abordagem.

Utilizamos cinco instrumentos de coleta de dados:

- Questionário inicial sobre o perfil do participante;

- Observação direta, cujo intuito foi captar as reações dos alunos durante o uso do jogo;

- Armazenamento do fluxo de movimentação do participante durante o jogo, para captar o desempenho do jogador e a usabilidade do jogo como, por exemplo, o tempo de jogo, o número de jogadas e o número de perguntas respondidas;

- Questionário pós-jogo para que o participante opinasse sobre usabilidade, dinâmica e estética do jogo;

- Entrevista com os alunos para coletar suas impressões após jogar.

As escolhas das cores e fonte do jogo não foram aleatórias. No caso das cores das casas do tabuleiro utilizou como referência as cores pigmentadas primárias opacas: amarelo, vermelho e azul. Quanto à fonte e seu tamanho, optou-se pela Arial, por ser uma fonte sem serifas, de instalação padrão nos computadores e semelhante à Aphont, utilizada no IBC. Seu tamanho ficou entre 20 e 24 , de acordo com a região livre da tela. 
Com os dados obtidos a partir dos instrumentos citados, utilizamos a abordagem de Mathison (1998) que trata da triangulação de dados, ou seja, o cruzamento de dados provenientes de instrumentos de coletas distintos, a fim de obter resposta sobre a questão proposta, o que nos permite verificar se os dados foram convergentes (quando dados de diferentes fontes ou coletados a partir de diferentes métodos concordam, o resultado é a convergência. ${ }^{8}$ ).

O processo ocorreu em mais de um ciclo, mediante ao apontamento dos alunos de necessidade de reformulações e acréscimos a serem feitos no jogo, os quais foram implementadas no ciclo 2, precisando serem repetidos os quatro últimos instrumentos de coletas de dados.

O intuito da metodologia aqui escolhida foi investigar a percepção dos alunos com deficiência visual em relação à utilização de um jogo digital construído para contribuir na apropriação de conhecimentos pedagógicos de forma lúdica.

\section{Resultados e Discussões}

Neste item, apresentamos uma análise acerca dos dados obtidos a partir de nossos cinco instrumentos de coleta já citados, com o objetivo final de estabelecer uma convergência entre eles de acordo com a triangulação de Mathison.

Cabe ressaltar que a efetiva participação na presente pesquisa dos sete alunos que se dispuseram a dela fazer parte, todos do ensino médio, só teve início após o preenchimento dos termos de assentimento e consentimento, conforme a idade do aluno. No intuito de manter o anonimato desses alunos, sempre que necessário, utilizamos a codificação aluno 1 até aluno 7 para destacar suas falas ou alguma emoção que se destaque durante as partidas.

\subsection{Análise da coleta de dados do perfil do aluno participante}

O questionário Perfil Do Aluno Participante foi o primeiro dos instrumentos de coleta de dados aplicado e que nos permitiu ter um perfil dos sujeitos da pesquisa.

Os alunos participantes têm idades entre 16 e 20 anos e, verificamos que 5 deles $(71,4 \%)$ são maiores de idade. Quanto ao sexo, também verificamos que 5 alunos $(71,4 \%)$ são do sexo masculino. Frisamos ainda que, entre os menores de idade, um é do sexo feminino e outro, do masculino.

A classificação dos alunos em possuidores de cegueira ou baixa visão deu-se com base no capítulo II do Decreto 5296 (BRASIL, 2004). Verificamos que os 3 alunos com baixa visão utilizam textos ampliados e os 3 alunos cegos utilizam textos em Braille. Além deles, há 1 aluno em fase de transição que não mais é capaz de ler textos em Aphont, 24 negrito, que é a utilizada pelo IBC, mas ainda não domina o sistema braile. Assumimos, portanto, que quatro alunos se configuram como cegos e três como alunos de baixa visão.

${ }^{8}$ When data from different sources or collected from different methods agree, the outcome is convergence. 
Os alunos foram convidados a selecionar até três TAs que mais utilizam dentre as seis opções disponíveis, como mostrado na Figura 4. Verificamos que os smartphones (mobile) representam importante meio de inclusão na vida destes alunos.

Figura 4 - Tecnologia Assistiva

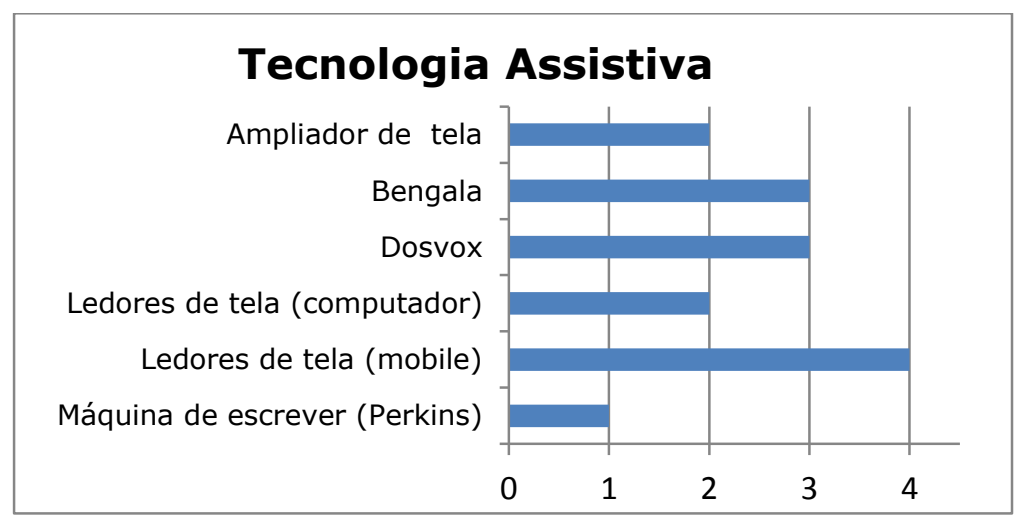

Fonte: o Autor, 2018.

Em relação ao pensamento dos alunos sobre a utilização de recursos digitais no ensino, apenas 1 aluno se mostrou contrário. Em seguida, questionamos se os alunos concordavam com a premissa de ser positivo o uso de jogos na aprendizagem, 6 alunos concordaram com esta premissa e apenas 1 aluno ainda não tem certeza sobre o fato. Ninguém se opôs. Estes dados são apresentados na figura 5 , a seguir.

Figura 5 -Jogos na Aprendizagem

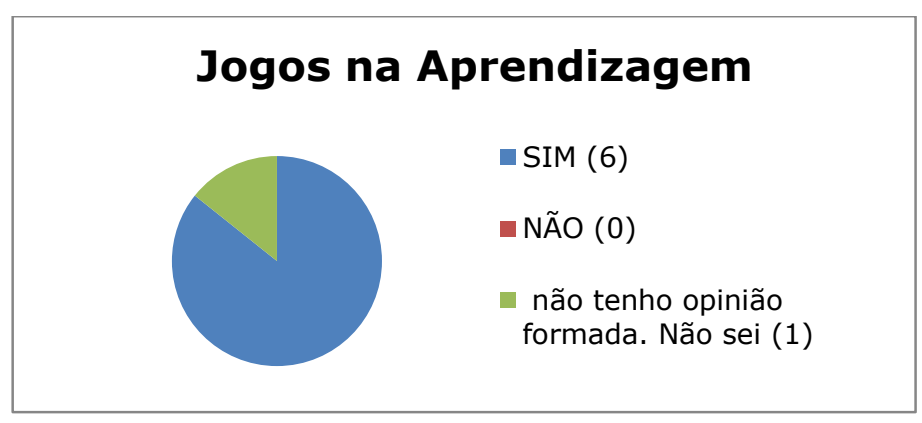

Fonte: o Autor, 2018.

Buscamos nos informar também sobre o nível de conhecimento desses alunos com o Jogavox, que está no cerne desta pesquisa.

No quesito relacionado ao Conhecimento sobre Jogavox (figura 6), verificamos que apenas 1 aluno $(14,3 \%)$ apontou não ter maior interesse pelo Jogavox mesmo já o conhecendo e, ainda assim, colocou-se à disposição de participar da pesquisa. Estimamos que com essa nova utilização reflita sobre as diversas possibilidades que o Jogavox proporciona e que, com isto, venha a recuperar seu interesse. Por outro lado, 2 deles (28,6\%), mesmo não sabendo utilizar o sistema, mostraram interesse em conhecer mais. Para estes, foram ensinados conceitos básicos necessários para acesso e utilização do programa Jogavox. 
Figura 6 - Conhecimento sobre o Jogavox

\begin{tabular}{|c|}
\hline Conhecimento sobre Jogavox \\
\hline $\begin{array}{l}\text { Sei utilizar } \\
\text { Tenho interesse de aprender mais (4) }\end{array}$ \\
\hline $\begin{array}{l}\text { Sei utilizar } \\
\text { Não tenho interesse de aprender mais (1) }\end{array}$ \\
\hline $\begin{array}{l}\text { Não sei utilizar } \\
\text { Tenho interesse de aprender mais (2) }\end{array}$ \\
\hline $\begin{array}{l}\text { Não sei utilizar } \\
\text { Não tenho interesse de aprender mais (0) }\end{array}$ \\
\hline
\end{tabular}

Fonte: o Autor, 2018.

Por fim, os alunos foram questionados acerca do uso de jogos digitais, de modo geral. Também quisemos saber sobre jogos já utilizados no Dosvox. Em especial, focamos explicitamente no Jogavox, com o intuito de descobrirmos que jogos eles já utilizaram, pedimos que explicitassem dois destaques e o motivo destas escolhas. Os dados obtidos estão no quadro 1.

Quadro 1 - Utilização de jogos no Jogavox

\begin{tabular}{|l|}
\hline \multicolumn{1}{|c|}{ Utilização de jogos no Jogavox } \\
\hline aluno 1 - Nenhum. \\
aluno 2 - Nenhum. \\
aluno 3 - Nenhum. \\
aluno 4 - Qual o instrumento. Ensina as crianças a conhecerem os instrumentos \\
musicais. \\
aluno 5 - Nenhum. \\
aluno 6 - Pandemia Mortal e Conto dos Cabritinhos. Eu considero os jogos \\
engraçados. \\
aluno 7 - Nenhum.
\end{tabular}

Fonte: O Autor, 2018.

Em relação ao Jogavox, cinco dos sete alunos não o utilizavam como meio de entretenimento ou aprendizagem. Isto nos fez refletir sobre sua eficácia na construção de jogos que atendam aos anseios dos alunos ou na sua divulgação. Este dado é um incentivo para esta pesquisa que visa corroborar com a utilização do Jogavox como meio de entretenimento e também de aprendizagem lúdica, por meio da construção e utilização de jogos.

\subsection{Comparativos dos ciclos de aplicação da pesquisa}

Foram feitas duas aplicações da pesquisa de modo a ter dados evolutivos a partir das modificações do jogo construídas em parceria com os 7 alunos participantes. Houve um intervalo de 2 semanas entre as aplicações de modo a contemplar tudo quanto fosse possível das sugestões dos alunos.

Cada ciclo é formado por quatro etapas: aplicação do jogo com observação participante do pesquisador, obtenção do relatório final do jogo, questionário pós-jogo e entrevista pós-jogo. 


\subsubsection{Análise comparativa da observação durante o jogo}

Ao aplicar o jogo, acompanhamos a partida de forma a coletar informações subjetivas acerca do interesse em continuar o jogo, sua jogabilidade e também sua compreensibilidade. O quadro 2 resume os resultados obtidos.

Quadro 2 - Comparativo observacional durante o jogo.

\begin{tabular}{|c|l|l|}
\hline Características & \multicolumn{1}{|c|}{ Ciclo 1 } & \multicolumn{1}{c|}{ Ciclo 2} \\
\hline Reações constantes & $\begin{array}{l}\text { Risos e murmúrios de dúvidas } \\
\text { sobre o conteúdo. Davam "cola" } \\
\text { entre si. }\end{array}$ & $\begin{array}{l}\text { Os murmúrios } \\
\text { permaneceram. }\end{array}$ \\
\hline Pergunta: Acerto e Erro & $\begin{array}{l}\text { Não demonstravam chateação e o } \\
\text { jogo fornece a resposta correta. }\end{array}$ & $\begin{array}{l}\text { Acréscimo de pistas para as } \\
\text { perguntas ajudaram a pensar } \\
\text { mais. }\end{array}$ \\
\hline Interesse no jogo & $\begin{array}{l}5 \text { alunos de 7 perguntaram "Pode } \\
\text { jogar de novo?" e jogaram. }\end{array}$ & $\begin{array}{l}5 \text { alunos de } 6 \text { sentiram vontade } \\
\text { de jogar de novo e jogaram. }\end{array}$ \\
\hline Tamanho da letra & $\begin{array}{l}\text { Pequena, mesmo aproximando } \\
\text { da tela. }\end{array}$ & $\begin{array}{l}\text { Houve melhora, mas consideram } \\
\text { que ainda precisa aumentar a } \\
\text { letra }\end{array}$ \\
\hline Tempo de jogo & 15 minutos & $\begin{array}{l}20 \text { minutos para duplas. } \\
8 \text { minutos para individual. }\end{array}$ \\
\hline
\end{tabular}

Fonte: o Autor.

Outras novidades apreciadas no ciclo 2:

> Gravação de partes do jogo com a voz de um dos autores, logo reconhecida pelos alunos;

> Acréscimo de efeitos sonoros, como o dado rolando. Os alunos alegaram gerar maior envolvimento (imersão) no jogo;

> Alteração no critério de vencedor do jogo: ganha quem fizer mais pontos e não quem chega primeiro. Com isso, torciam para cair em casa de perguntas e ganhar pontos;

$>$ Poder jogar com 1 ou 2 jogadores;

$>$ Mudanças de parte das casas vazias (amarelas) para casas de perguntas (azuis).

Houve diversos comentários positivos sobre as mudanças implementadas e foi claro o sentimento de contribuição uma vez que participaram ativamente na melhora do produto a partir das colocações do ciclo 1 da aplicação. Acreditamos que a ludicidade foi um aspecto motivador da aprendizagem uma vez que os alunos participantes se empolgavam e queriam jogar mais, participar mais e acertar mais.

\subsubsection{Descrição comparativa do arquivo gerado ao final da partida}

O jogo foi construído de modo que, ao final de cada partida, um arquivo resumo avaliativo é gerado. Com este arquivo, é possível averiguar a média de rodadas necessárias para completar a partida, o desempenho de cada participante em relação ao conteúdo, incluindo a quantidade de perguntas recebidas, os erros e acertos entre outras informações.

No ciclo 1, observamos que o número de rodadas variou entre 9 e 13. No ciclo 2, também obtivemos a mesma variação. 
Esta variação tem influência de três fatores:

- A magnitude do valor obtido ao lançar o dado;

- O sorteio da casa de Sorte ou Azar;

- Resposta às perguntas;

- No caso de acerto, permanece na posição atual;

- No caso de erro, retorna à posição anterior.

Pretende-se que esse instrumento auxilie o professor que aplicar o jogo na sua turma a adaptá-lo de modo que cada vez mais se adeque à realidade do seu alunado.

\subsubsection{Análise comparativa do questionário pós-jogo}

Após cada um dos ciclos de avaliação, reaplicamos o questionário pós-jogo, baseado na escala de Likert $^{9}$ (os valores 1, 2, 3, 4 e 5 são, respectivamente, discordo totalmente, discordo em parte, não concordo nem discordo, concordo em parte e concordo totalmente. O X representa a opção quando a assertiva não cabe àquela pessoa). Este questionário procurou subsidiar a análise que avaliou a qualidade do produto desenvolvido nesta pesquisa. Estas informações estão em forma de comparativo entre o ciclo 1 e o ciclo 2, a partir das modificações feitas no jogo com base nas avaliações dos alunos. Optamos por dividir estas informações nas tabelas 1, 2 e 3, contendo 4 perguntas em cada.

Tabela 1 - Questionário pós-jogo - Parte 1

\begin{tabular}{|c|c|c|c|c|c|c|c|c|c|c|c|c|c|}
\hline \multirow{3}{*}{\multicolumn{2}{|c|}{ Assertivas }} & \multicolumn{12}{|c|}{ Escala de Likert } \\
\hline & & \multicolumn{6}{|c|}{ Ciclo 1} & \multicolumn{6}{|c|}{ Ciclo 2} \\
\hline & & 1 & 2 & 3 & 4 & 5 & $\mathbf{x}$ & $\mathbf{1}$ & 2 & 3 & 4 & 5 & $\mathbf{x}$ \\
\hline 1. & $\begin{array}{l}\text { As explicações das regras e descrição das casas do } \\
\text { tabuleiro foram compreensíveis. }\end{array}$ & 0 & 1 & 0 & 0 & 6 & 0 & 0 & 0 & 0 & 0 & 6 & 0 \\
\hline 2. & $\begin{array}{l}\text { As informações para localizar onde está a peça do } \\
\text { tabuleiro foram suficientes. }\end{array}$ & 0 & 0 & 1 & 0 & 6 & 0 & 0 & 0 & 0 & 0 & 6 & 0 \\
\hline 3. & Senti vontade de continuar a partida até o final. & 0 & 0 & 0 & 0 & 7 & 0 & 0 & 0 & 0 & 0 & 6 & 0 \\
\hline 4. & O jogo me estimulou a estudar de forma lúdica. & 0 & 1 & 1 & 2 & 3 & 0 & 0 & 0 & 0 & 1 & 5 & 0 \\
\hline
\end{tabular}

Fonte: o Autor, 2018

Os resultados do ciclo 2 apontam a manutenção ou melhora em todas as assertivas deste primeiro bloco.

Percebemos que $100 \%$ dos alunos tiveram plena compreensão de como o jogo estava montado e quais são suas regras, o que nos mostra um ganho de 14,3\% em relação ao ciclo 1 . Os mesmos $100 \%$ também conseguiram identificar a localização de sua peça no tabuleiro, também superando o resultado alcançado no ciclo 1, que era de $85,3 \%$.

O fato de já conhecerem o jogo não parece ter impacto negativamente, já que 100\% deles continuam com o mesmo entusiasmo de seguir a partida até o final. Uma mudança bastante

${ }^{9}$ É uma escala de satisfação ou grau de concordância das proposições feitas ao respondente. 
significativa é o fato de, no ciclo 2 , ter aumentado para $83,3 \%$ o percentual de alunos que concordam totalmente com o jogo ter estimulado a estudar de forma lúdica, e os outros $16,7 \%$ concordarem em parte com tal afirmação. Isto nos evidencia que as mudanças feitas no jogo viabilizam que este viés possa também ser um meio de aprendizagem. O total de participantes favoráveis é agora de $100 \%$ contra $71,5 \%$ do ciclo 1 .

Tabela 2 - Questionário pós-jogo - Parte 2

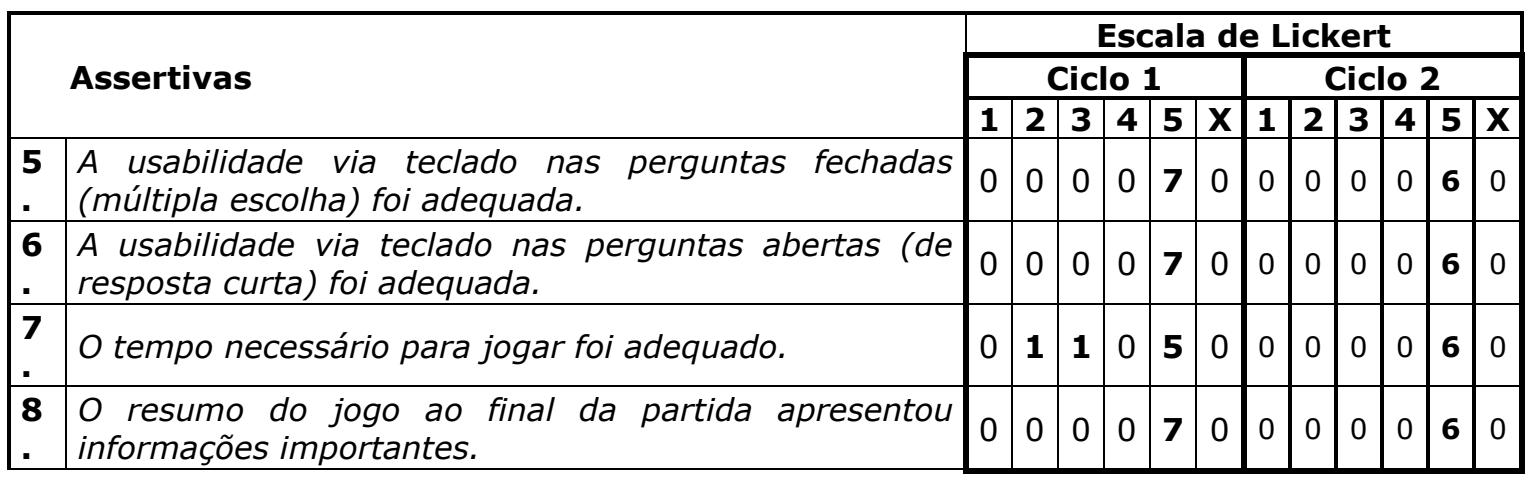

Fonte: o Autor, 2018.

As questões 5, 6 e 8 foram aprovadas por $100 \%$ dos alunos, mesmo fator alcançado no ciclo 1. Em relação ao tempo de jogo, na questão 7 , houve um acréscimo em sua aprovação, alcançando os $100 \%$. No ciclo 1 , eram apenas $71,5 \%$ dos alunos que apreciavam o tempo utilizado por partida.

Tabela 3 - Questionário pós-jogo - Ciclo 1 - Parte 3

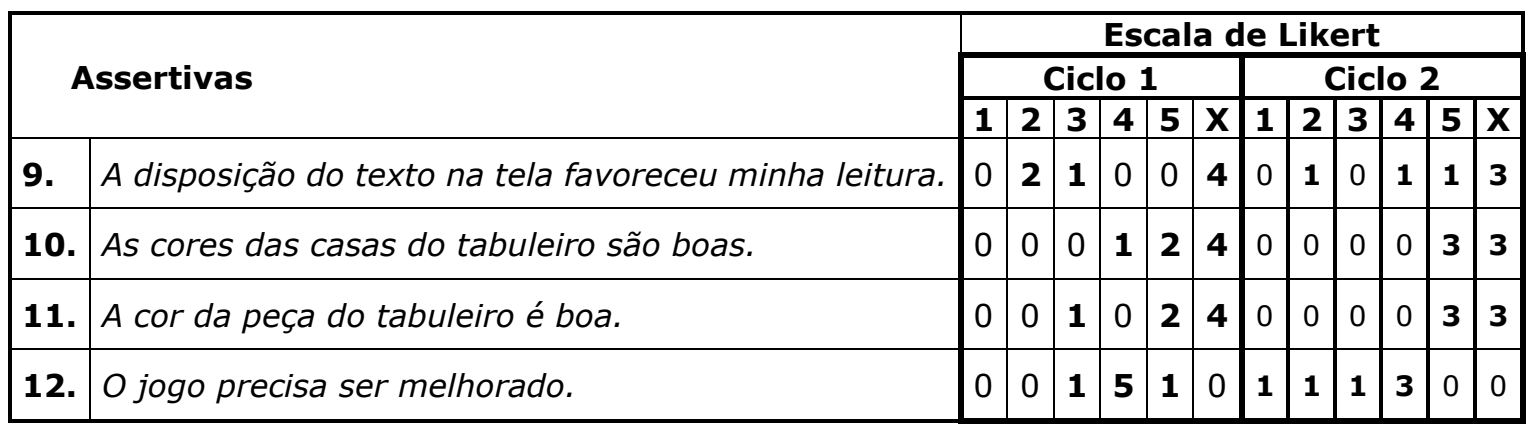

Fonte: o Autor, 2018.

A pergunta 12 é de suma importância para avaliação de necessidade de mudanças no jogo. Com base nesta pergunta, sobre o jogo precisar ser melhorado, 14,3\% consideram o jogo regular, outros $14,3 \%$ consideram que o jogo precisa totalmente de melhora e $71,4 \%$ consideram a necessidade de melhora, ainda que reconheçam características positivas do jogo. Isto aponta a necessidade de reformulações, as quais foram implementadas para a aplicação do ciclo 2.

As perguntas 9, 10 e 11, abordam questões visuais e, portanto, ela não se aplica a 57\% dos participantes. Utilizaremos como referência os outros 3 participantes que, são os três com baixa visão. Houve uma melhora na avaliação da disposição no texto da tela, ainda assim, um dos alunos $(33,3 \%)$ considerou que o texto ainda estava muito ruim para ser lido. Os outros 2 
$(66,6 \%)$ consideraram bom ou ótimo. Em relação às cores das casas, tivemos uma elevação para $100 \%$ dos alunos aprovando as novas cores da casa. Acreditamos que isto seja consequência da diminuição do quantitativo de casas amarelas, já que estas, por vezes, confundiam-se com a peça branca.

Com relação a melhoras futuras do jogo, tivemos 16,7\% desconsiderando qualquer necessidade de mudança no jogo. Outros $16,7 \%$ consideram que ainda há alguns pontos a melhorar. Ainda um grupo de 16,7\% não tem muito certeza sobre esta necessidade, mas não se coloca contra. Entretanto, 50\% ainda considera a necessidade de evolução do jogo, para abarcar cada vez mais funcionalidades e, também, agregar conhecimentos. Um dos possíveis motivos pode ter sido a não inserção de outras disciplinas.

\subsubsection{Análise da entrevista pós-jogo}

Cada aluno foi entrevistado, podendo detalhar questões de pontos positivos e negativos do jogo e da sua dinâmica e sugestões de melhora. Também questionamos cada um sobre a possibilidade de apropriação deste conhecimento por outros professores e por eles mesmo, através de minicursos voltados ao desenvolvimento de novos jogos. Foi possível estabelecer uma correlação entre as respostas obtidas na entrevista com as observações feitas durante o jogo. Estas informações estão sintetizadas no quadro 3, para o ciclo 1 e no quadro 4, para o ciclo 2.

Quadro 3 - Entrevista pós-jogo - Ciclo 1

\begin{tabular}{|c|c|}
\hline \multicolumn{2}{|c|}{ 1. Sentiu-se angustiado em algum momento da partida? Qual? } \\
\hline Avaliação & $\begin{array}{l}\text { De modo geral, os alunos não tiveram problema. O aluno } 1 \text { relatou não estar confortável } \\
\text { com o tamanho da letra, achando-a pequena, mas compensada pelo áudio e o aluno } 6 \\
\text { demonstrou insegurança na questão referente ao conteúdo. }\end{array}$ \\
\hline \multicolumn{2}{|c|}{$\begin{array}{l}\text { 2. As informações escritas na tela (ou lidas pelo sintetizador) foram suficientes para entender o que estava } \\
\text { ocorrendo? Comente. }\end{array}$} \\
\hline Avaliação & $\begin{array}{l}\text { Quase todos responderam sim, somente o aluno } 5 \text { se manifestou em contrário e afirmou que } \\
\text { precisava da letra maior, pois ele prefere ler. O aluno } 7 \text { não teve problema, mas nos informou } \\
\text { que a palavra "inócua" não foi bem pronunciada pelo sintetizador. }\end{array}$ \\
\hline \multicolumn{2}{|c|}{$\begin{array}{l}\text { 3. Quanto à aparência (estética), o jogo está bem disposto na tela e facilitou a compreensão da proposta? } \\
\text { (para quem couber). Comente. }\end{array}$} \\
\hline Avaliação & Os alunos com baixa visão falaram que a informação é compreensível. \\
\hline \multicolumn{2}{|c|}{ 4. Quais as qualidades positivas do jogo, virtudes e acertos? } \\
\hline Aval & $\begin{array}{l}\text { A questão da aprendizagem foi abordada por } 6 \text { dos } 7 \text { alunos, como são mostradas a seguir: } \\
\text { a) aluno } 1 \text { - "Tem de bom é a questão da aprendizagem". } \\
\text { b) aluno } 2 \text { - "No jogo deu para aprender coisas que temos dúvidas no dia a dia.". } \\
\text { c) aluno } 3 \text { - "Ele é bom porque a pessoa pode estudar de uma maneira muito mais dinâmica } \\
\text { [...] é um modo muito mais prático de aprender os conteúdos". } \\
\text { d) aluno } 4 \text { - "Ele proporciona uma maior interatividade do deficiente visual ao mundo dos } \\
\text { jogos." } \\
\text { e) aluno } 6 \text { - "Ele usou o conteúdo que eu tava estudando, como calorimetria, temperatura" } \\
\text { f) aluno } 7 \text { - "Tem a parte do conhecimento que é boa.". "É um jogo que estimula você a } \\
\text { querer continuar." }\end{array}$ \\
\hline \multicolumn{2}{|c|}{ 5. Quais as qualidades negativas do jogo, ou seja, vícios e falhas? } \\
\hline Avaliação & $\begin{array}{l}\text { Os alunos com baixa visão (3) apontaram que a fonte estava pequena. } \\
\text { Um dos alunos afirmou que tinham poucas casas de perguntas e um outro, que deveriam } \\
\text { ter outros gêneros de perguntas. } \\
\text { Há um aluno que não gostou da música da entrada e outro aluno disse que preferia que } \\
\text { fosse tudo gravado, pois não gosta das vozes sintetizadas. }\end{array}$ \\
\hline \multicolumn{2}{|c|}{ 6. Que características ou funcionalidades você gostaria que uma nova versão do jogo tivesse? } \\
\hline Avaliação & $\begin{array}{l}\text { As funcionalidades sugeridas pelos alunos foram: } \\
\text { - aumentar o número de casa de perguntas, } \\
\text { - aumentar a dificuldade das perguntas conforme avance no tabuleiro, } \\
\text { - ter pistas em todas as perguntas }\end{array}$ \\
\hline
\end{tabular}




\begin{tabular}{|c|c|}
\hline & $\begin{array}{l}\text { - ter mais possibilidades de jogadores }(1,2,3, \ldots \text { não só duplas), } \\
\text { - inserir mais opções de disciplinas, } \\
\text { - inserir mais sonoplastia. } \\
\text { - ganhar o jogo quem tiver mais pontos. }\end{array}$ \\
\hline Avaliação & $\begin{array}{l}\text { Todos afirmaram que sim e, em particular, o aluno } 5 \text { afirmou que "O estudo com a diversão, } \\
\text { como este jogo mesmo tem. Ele ajuda muito." }\end{array}$ \\
\hline Avaliação & $\begin{array}{l}\text { De modo geral, } 6 \text { dos } 7 \text { alunos são favoráveis, mas há algumas divergências na forma, pois } \\
\text { há quem acredite que deveria começar do fundamental e depois dar seguimento. Outro aluno } \\
\text { afirma que os professores já deveriam ter aprendido. Outros } 2 \text { alunos apontam que deveria } \\
\text { ser apresentado para aqueles professores que demonstrarem interesse pelo tema. } \\
\text { O único aluno discordante revela o medo de achar que ensinando isto aos professores, eles } \\
\text { acharão que o aluno com DV só vai querer jogo e poderão não trabalhar com os demais } \\
\text { recursos inclusivos. }\end{array}$ \\
\hline Avaliação & $\begin{array}{l}\text { Entres os participantes, } 3 \text { alegaram que não e, como justificativa de dois deles, não ter } \\
\text { prazer ou "perfil" para informática (na parte da produção) pois não gostam. Entre os que } \\
\text { concordam, houve comentário relativo ao estudo como menciona o aluno } 1 \text { "O jogo tem um } \\
\text { arranjo que ele te atrai. Poder de atração que o jogo tem. Ajudaria bastante no estudo" e } \\
\text { também o aluno } 5 \text { fala sobre o jogo voltado ao estudo. "É um recurso de estudo que ajuda } \\
\text { a pessoa" }\end{array}$ \\
\hline \multicolumn{2}{|c|}{$\begin{array}{l}\text { 10. Caso haja algo adicional a mencionar, por não terem sido contempladas nas perguntas, fique à } \\
\text { vontade. }\end{array}$} \\
\hline Avaliação & $\begin{array}{l}\text { Nesta pergunta, os alunos citaram, por vezes, propostas que outros já tinham feito. Foram } \\
\text { lembradas questões como: } \\
\text { a) inserir sonoplastia; } \\
\text { b) abertura a outras disciplinas em tabuleiro próprio ou misturado; } \\
\text { c) aumento do tempo do jogo, assumindo que quanto mais tempo, mais estudo; } \\
\text { d) jogadores ligados via Internet; } \\
\text { e) acréscimo de outras atividades do jogo, como, por exemplo, o sugerido pelo aluno } 7 \\
\text { "escolha um jogador para retornar X casas". }\end{array}$ \\
\hline
\end{tabular}

Fonte: o Autor, 2018.

Com base nas respostas a estas entrevistas, no ciclo 1, podemos sintetizar que o Jogo é inclusivo e positivo desde que ele não seja utilizado como substitutivo de outras tecnologias de acesso, mas sim uma opção a mais disponível para o uso de pessoas com e sem deficiência visual. Ademais, as questões do conteúdo e da aprendizagem foram amplamente citadas pelos alunos, de modo que eles enxergam nos jogos não apenas entretenimento, mas também uma forma lúdica de aquisição de conteúdo.

Quadro 4 - Entrevista pós-jogo - Ciclo 2

\begin{tabular}{|l|l|}
\hline \multicolumn{2}{|l|}{ 1. Sentiu-se angustiado em algum momento da partida? Qual? } \\
\hline Avaliação & $\begin{array}{l}\text { De modo geral, os alunos não tiveram problema. O aluno } 1 \text { relatou não estar confortável } \\
\text { com a leitura das opções pelo sintetizador quando falava a letra da opção. O aluno } 6 \text { relatou } \\
\text { ter se confundido no uso do teclado pressionando a letra da opção escolhida mais de uma } \\
\text { vez, antes de dar enter, o que ocasionou o entendimento de erro pelo jogo. }\end{array}$ \\
\hline $\begin{array}{l}\text { 2. As informações escritas na tela (ou lidas pelo sintetizador) foram suficientes para entender o que estava } \\
\text { ocorrendo? Comente. }\end{array}$ \\
\hline Avaliação & $\begin{array}{l}\text { Neste ciclo, todos os alunos responderam que sim e o aluno 4, por exemplo, acrescentou } \\
\text { que "Tudo foi fornecido com a maior riqueza de detalhes. Nada escapou. E tá ótimo" }\end{array}$ \\
\hline $\begin{array}{l}\text { 3. Quanto à aparência (estética), o jogo está bem disposto na tela e facilitou a compreensão da proposta? } \\
\text { (para quem couber). Comente. }\end{array}$ \\
\hline Avaliação & $\begin{array}{l}\text { Os alunos com baixa visão falaram que a informação é compreensível, mas que seria ainda } \\
\text { melhor aumentando o contraste com a imagem de fundo. }\end{array}$ \\
\hline 4. Quais as qualidades positivas do jogo, virtudes e acertos?
\end{tabular}




\begin{tabular}{|c|c|}
\hline Avaliação & $\begin{array}{l}\text { Neste segundo ciclo de aplicação os alunos apontaram o acolhimento das modificações } \\
\text { propostas por eles como pontos positivos sem deixar de mencionar a importância que isto } \\
\text { tem na aprendizagem do conteúdo: } \\
\text { - Aumento das casas de perguntas, que propiciaram mais oportunidade de aprendizagem; } \\
\text { - Gravações na voz do autor em algumas partes e a inserção das pistas tornaram o jogo } \\
\text { mais dinâmico. As pistas também ajudaram na aprendizagem; } \\
\text { - Partida para } 1 \text { ou } 2 \text { jogadores; } \\
\text { - Revisão de conteúdo. }\end{array}$ \\
\hline \multicolumn{2}{|c|}{ 5. Quais as qualidades negativas do jogo, ou seja, vícios e falhas? } \\
\hline Avaliação & $\begin{array}{l}\text { Dois alunos com baixa visão, apesar do aumento do tamanho da fonte, ainda apontaram que } \\
\text { esta estava pequena. } \\
\text { Outros dois alunos frisaram que a presença da voz sintetizada não é muito apreciável e } \\
\text { prefeririam que tivesse mais voz humana, tornando o som mais agradável ao participante. } \\
\text { A música da Adelle permaneceu, desagradando um dos alunos. }\end{array}$ \\
\hline \multicolumn{2}{|c|}{ 6. Que características ou funcionalidades você gostaria que uma nova versão do jogo tivesse? } \\
\hline Avali & $\begin{array}{l}\text { As funcionalidades sugeridas pelos alunos foram: } \\
\text { - aumentar a dificuldade das perguntas conforme avance no tabuleiro e criar fases; } \\
\text { - limitar a quantidade de pistas a serem usadas pelo participante; } \\
\text { - ter mais possibilidades de quantidade de jogadores por partida (1, } 2 \text { ou mais); } \\
\text { - inserir mais opções de disciplinas; }\end{array}$ \\
\hline \multicolumn{2}{|c|}{ 7. Gostaria de aprender outros conteúdos a partir de jogos desenvolvidos no Jogavox? } \\
\hline Avali & $\begin{array}{l}\text { Todos afirmaram que sim e há de se destacar a fala do aluno } 4 \text { quando este diz "Sem sombra } \\
\text { de dúvida" e o aluno } 5 \text {, que acredita serem os jogos benéficos "até para pessoas que tenham } \\
\text { alguns problemas de concentração" }\end{array}$ \\
\hline \multicolumn{2}{|c|}{$\begin{array}{l}\text { 8. Qual sua opinião quanto a professores aprenderem a utilizar o Jogavox para desenvolverem jogos para } \\
\text { o processo de inclusão? }\end{array}$} \\
\hline Avaliação & $\begin{array}{l}\text { De modo geral, } 5 \text { dos } 6 \text { alunos são favoráveis, mesmo havendo algumas diferenças na } \\
\text { motivação. Todos enxergam que este processo de inclusão mediado pelo Jogavox e voltado } \\
\text { ao aprendizado dos conteúdos é uma importante estratégia de fixação ou aquisição de } \\
\text { conteúdos. O aluno } 3 \text { enfatizou que "Eu acho importante, pois assim eles vão poder, de } \\
\text { acordo com suas disciplinas, criar jogos focados em determinados conteúdos que os alunos } \\
\text { apresentam maior dificuldade tendo uma forma mais dinâmica e agradável, tudo se torna } \\
\text { mais compreensível" } \\
\text { O único aluno discordante, aluno 4, entende que estes jogos produzidos no Jogavox devam } \\
\text { estar bem revistos, modificados pelos seus autores e prontos, de tal maneira que os } \\
\text { professores só inseririam seus conteúdos, não deixando margem para um pensamento que } \\
\text { segundo ele é comum, no qual "ia reforçar aquela ideia de que o cego só brinca". }\end{array}$ \\
\hline \multicolumn{2}{|c|}{$\begin{array}{l}\text { 9. Você gostaria, em momento futuro, de participar de curso (ou oficina) para aprender a criar jogos no } \\
\text { Jogavox a fim de ajudar na sua aprendizagem e na de outros? }\end{array}$} \\
\hline Avaliação & $\begin{array}{l}\text { Neste segundo ciclo, apenas um dos alunos manteve sua posição de não ter interesse de } \\
\text { participar destes cursos. Portanto, } 1 \text { aluno mudou de posição, o aluno } 4 \text {. Este fez uma } \\
\text { afirmação muito enfática, afirmando que "Sim, Justamente. Pensaria sim, com o intuito de } \\
\text { trazer conhecimento. De avançar no nível intelectual do indivíduo, mas não assim de tratar } \\
\text { só como uma brincadeira. Ser mais do que uma brincadeira. Uma oportunidade de inclusão. } \\
\text { Uma Oportunidade de aprendizado". Esta opinião corrobora com a proposta deste projeto. }\end{array}$ \\
\hline \multicolumn{2}{|c|}{$\begin{array}{l}\text { 10. Caso haja algo adicional a mencionar, por não terem sido contempladas nas perguntas, fique à } \\
\text { vontade. }\end{array}$} \\
\hline
\end{tabular}

Fonte: o Autor, 2018.

Percebemos a satisfação dos alunos ao jogarem a versão 2.0 do jogo que continha muitas de suas contribuições e, nos respaldando em Papert (1993), entendemos que eles estavam 'pescando', ou seja, construindo o conhecimento, independentemente da programação.

De acordo com Huizinga (2010), a ludicidade não é antagônica à seriedade e, como já havíamos mencionado, duas pessoas jogando xadrez não estão rindo e, ainda assim, é uma atividade lúdica. Em nosso jogo, os alunos queriam conquistar mais pontos para ganhar a partida e nesse processo, ganhavam conhecimento, autonomia e reconhecimento.

No âmbito das TAs, o Jogavox passou a ter um lugar de relevância para o grupo pesquisado. O desinteresse pelos jogos do Jogavox, evidenciado pelo quadro 1, no qual só 2 alunos apontaram 
terem jogado algum de seus jogos, foi superado, e 100\% deles passaram a ter interesse de jogar outros jogos para se divertir e aprender.

Quanto à inclusão, respaldada pela LDB (1996), caracterizamos o jogo como inclusivo, tendo em vista que há recursos imagéticos e sonoros e efetivamente permite a participação conjunta de pessoas com e sem deficiência visual. Ainda acreditamos que pessoas com outras especificidades poderiam utilizar o jogo sem maiores dificuldades, por conta da sua simplicidade da interação.

\section{Considerações Finais}

Este artigo visa uma mensagem em prol da contínua luta para uma inclusão total. Focamos a questão da deficiência visual como propulsora desta discussão e destacamos que uma deficiência não deva ser impeditiva para participação plena do cidadão na sociedade.

O jogo digital, aqui apresentado, foi construído de forma participava com alunos com deficiência visual, abarcando elementos funcionais, auditivos e imagéticos. Este jogo tem o intuito de estimular a utilização de recursos lúdicos para a aquisição de conhecimento e ser inclusivo.

Apresentamos também uma tecnologia digital de custo zero, o Sistema Dosvox e, integrado a ele, o programa Jogavox, no qual foi construído o jogo Trilha do Conhecimento.

Acreditamos que ele tenha atendido o propósito de ser inclusivo, uma vez que suas informações pareceram claras e o modo de interação se mostrou bem simples o que viabiliza que pessoas com outras deficiências e pessoas que não dominam a informática possam fazer uso do mesmo.

Finalizando gostaríamos de deixar registrada nossa crença no seu poder transformador e nossa expectativa de que o leitor se sinta impelido a desenvolver outras propostas inclusivas, criativas, inovadoras e significativas na busca de uma educação cada vez mais emancipadora, autônoma, crítica e para todos.

\section{Referências}

BRASIL. Constituição da República Federativa do Brasil. Brasília: Senado Federal, 1988. Disponível em: <http://www.planalto.gov.br/ccivil_03/constituicao/constituicao.htm>. Acesso em: 12 jan. 2018.

- Decreto da Promoção de acessibilidade às pessoas portadoras de deficiência e com acessibilidade reduzida. DECRETO No 5.296. Brasília, 2004. Disponível em: <http://www.planalto.gov.br/ ccivil_03/_ato2004-2006/2004/decreto/d5296.htm>. Acesso em: 4 abr. 2018.

. Lei de Diretrizes e Bases da Educação Nacional - Lei no 4.024. Brasília: Senado Federal, 1961 Disponível em: <http://www.planalto.gov.br/Ccivil_03/leis/L4024.htm>. Acesso em: 12 jan. 2018.

Lei de Diretrizes e Bases da Educação Nacional - Lei no 9.394. Brasília: Senado Federal, 1996. Disponível em: <http://www.planalto.gov.br/Ccivil_03/leis/L9394.htm>. Acesso em: 12 jan. 2018.

. Lei Brasileira da Inclusão da Pessoa com Deficiência - Lei no 13.146. Brasília: Senado Federal, 2015. Disponível em: <http://www.planalto.gov.br/ccivil_03/_ato2015-2018/2015/lei/l13146.htm>. Acesso em: 12 jan. 2018.

CUNHA, Erica Esteves. Jogavox: ferramenta e estratégias para construção de jogos educacionais para deficientes visuais. Dissertação de Mestrado. Rio de Janeiro: UFRJ, 2007. Disponível em: <http://intervox.nce.ufrj.br/ tiagoborges/jogavox/textos/EricaEstevesCunha.pdf>. Acesso em: 28 fev. 2017. 
HILDEBRAND, Hermes Renato; OLIVEIRA, Fabiana Martins de. Ludicidade, Ensino e Aprendizagem nos Jogos Digitais Educacionais. Informática na Educação: teoria \& prática, Porto Alegre, V. 21, n. 1, p. 106-120, jan./abr. 2018. Disponível em: <http://seer.ufrgs.br/InfEducTeoriaPratica/article/download/59479/ 49425>. Acesso em:12 set. 2018 .

HUIZINGA, Johan. Homo Ludens: o jogo como elemento da cultura. 6. ed. São Paulo: Perspectiva, 2010. (Coleção Estudos).

MATHISON, Sandra. Why Triangulate? Educational Researcher, v17 n2 p13-17 Mar 1988. Disponível em: <https://blogs.baruch.cuny.edu/com9640/files/2010/08/whytriangulate.pdf>. Acesso em: 7 jun. 2018.

OCHAÍTA, Esperanza; ESPINOSA, Maria Ángeles. Desenvolvimento e intervenção educativa nas crianças cegas ou deficientes visuais. In: COLL, César; MARCHESI, Álvaro; PALACIOS, Jesús (Org.). Desenvolvimento psicológico e educação. Porto Alegre: Artmed, 2004. 3v (Coleção Transtornos do desenvolvimento e necessidades educativas especiais).

PAPERT, Seymor. The Children's Machine: rethinking school in the age of the computer. New York: BasicBooks, 1993. Disponível em <http://learn.media.mit.edu/lcl/resources/readings/childrensmachine.pdf>. Acesso em: 06 jul. 2018.

PAULA, Bruno Henrique de; VALENTE, José Armando. Jogos digitais e educação: uma possibilidade de mudança da abordagem pedagógica no ensino formal. Revista Ibero-americana de Educação, v. 70, n 1, p. 9-28, 2016

SASSAKI, Romeu, K. Inclusão. Construindo uma sociedade para todos. Rio de Janeiro: WVA, 1997.

SILVA, Lidiane Figueira da. Geometria e cegos - Um jogo computacional no processo de aprendizagem de trigonometria. Rio de Janeiro, 2009. Monografia de final do curso apresentada ao Programa de Pós-Graduação Lato Sensu em Tecnologias da Informação Aplicadas à Educação (PGTIAE), do Núcleo de Computação Eletrônica da Universidade Federal do Rio de Janeiro, Rio de Janeiro, 2008. Disponível em: <http://intervox.nce.ufrj.br/ tiagoborges/jogavox/textos/monografia_lidiane.pdf>. Acesso em: 30 mar. 2018.

SILVA, Wesley Pereira da. Jogos digitais adaptados para estudantes com deficiência visual: estudo das habilidades cognitivas no Dosvox. 2017. 145 f., il. Dissertação (Mestrado em Educação)-Universidade de Brasília, Brasília, 2017. <http://repositorio.unb.br/bitstream/10482/23348/1/2017_WesleyPereirada Silva.pdf>. Acesso em: 15 jan. 2018.

TRIVIÑOS, Augusto N. Introdução à pesquisa em Ciências Sociais - a pesquisa qualitativa em educação. São Paulo: Atlas, 1987.

VALENTE, José Armando. Diferentes usos do computador na educação. In: Computadores e conhecimento: repensando a educação. $2^{\mathrm{a}}$ ed. Campinas: NIED-Unicamp, 1998.

Recebido em setembro de 2018

Aprovado para publicação em abril de 2019

\section{Bruno Cesar Soares Dile Robalinho}

Programa de Mestrado Profissional em Práticas de Educação Básica - Colégio Pedro II - CPII, Brasil, brunopedagogo.cp2@gmail.com

\section{Christine Sertã Costa}

Programa de Mestrado Profissional em Práticas de Educação Básica - Colégio Pedro II - CPII, Brasil, cserta@globo.com 